\title{
EL CONTROL EMPRESARIAL DEL USO DE DISPOSITIVOS DIGITALES CON FINES SINDICALES ${ }^{1}$
}

\author{
Francisco Andrés Valle Muñoz ${ }^{2}$. \\ Profesor Titular de Derecho del Trabajo y de la Seguridad Social. \\ Acreditado a Catedrático de Universidad. \\ Universidad Pompeu Fabra, Barcelona.
}

\begin{abstract}
Las nuevas tecnologías de la información y de la comunicación han facilitado la labor informativa del sindicato en la empresa a través del correo electrónico, el tablón digital o la conexión a internet, pero también han ampliado los poderes de control empresarial en esta materia. Siendo ello así, el empresario no puede fiscalizar las comunicaciones sindicales accediendo al contenido de los correos electrónicos o de los archivos remitidos por el sindicato para su publicación en el tablón digital, porque vulneraría no solo el derecho al secreto de las comunicaciones sino también el derecho de libertad sindical. El control empresarial sólo estaría justificado para evitar ciertos riesgos derivados de un uso abusivo o desviado de los dispositivos digitales y debería respetar en todo caso el conocido principio de proporcionalidad.
\end{abstract}

The new information and communication technologies have facilitated the informative work of the trade union in the company through email, the digital board or the internet connection, but they have also expanded the powers of corporate control in this matter. At this point, the employer cannot control these communications by accessing the content of the emails or files sent by the trade union for publication on the digital board, because it would violate the right to secrecy of communications and the right to freedom of association. Business control would only be justified to avoid certain risks arising from abusive or deviated use of digital devices and should respect the principle of proportionality.

Title: The business control of digital devices uses for trade union purposes

Palabras clave: Control empresarial; dispositivos digitales; información sindical.

Key words: Business control; digital devices; trade union information.

\footnotetext{
${ }^{1}$ El presente estudio ha sido desarrollado en el marco del proyecto de investigación titulado: "Nuevas tecnologías, cambios organizativos y trabajo: una visión multidisciplinar" (2019-2021), a cargo del Ministerio de Ciencia, Innovación y Universidades, y con número de referencia: RTI2018-097947-B-I00.

${ }^{2}$ Miembro del grupo de investigación consolidado reconocido por la Generalitat de Cataluña: "Social and Business Research Laboratory” (SBRLab). Ref. 2017 SGR 1572.
} 
IUSLabor 3/2020, ISSN 1699-2938, p. 101-122.

DOI. 10.31009/IUSLabor.2020.i03.04

Fecha envío: 23.07.2020 | Fecha aceptación: 28.09.2020

\section{Sumario}

1. Introducción.

2. El uso de dispositivos digitales con fines sindicales.

3. La inexistente regulación legal sobre el control empresarial del uso de dispositivos digitales con fines sindicales.

4. La regulación convencional.

5. El tratamiento jurisprudencial.

6. Conclusiones.

7. Bibliografía. 


\section{Introducción.}

En la década de los sesenta del siglo pasado, el modelo de sociedad industrial empezó a ceder protagonismo a otro modelo distinto basado en el procesamiento y manejo de la información (principalmente a través de medios informáticos), acuñándose el concepto de "sociedad del conocimiento" o "sociedad de la información", en la que han jugado un papel decisivo las llamadas nuevas tecnologías de la información y de la comunicación. Las mismas, en términos generales, han sido definidas ${ }^{3}$ como aquél conjunto de instrumentos que se han ido desarrollando a lo largo de las últimas décadas para facilitar la comunicación y la transmisión de información (mediante ordenadores, telefonía móvil, correo electrónico, internet, etc.), y que han afectado de manera directa a aspectos claves de la vida diaria, pero también de las relaciones laborales, al incidir en los procesos productivos de cualquier economía de mercado.

En este punto, se habla abiertamente de que en la actualidad estamos viviendo una nueva revolución tecnológica conocida como cuarta revolución industrial, o industria 4.0, de modo que si en el último tercio del siglo XX presenciamos la incorporación de las entonces llamadas "nuevas tecnologías" vinculadas a la informática y a las telecomunicaciones, en el actual escenario estas mismas técnicas han evolucionado en el terreno de la digitalización y de la conectividad ${ }^{4}$.

En este contexto, las nuevas tecnologías de la información y de la comunicación también han incidido en el poder de vigilancia y control empresarial de la prestación de trabajo, ampliándolo de diversas maneras, con los riesgos que ello supone a la hora de vulnerar derechos fundamentales del trabajador ${ }^{5}$. Precisamente este control empresarial puede afectar tanto al derecho a la intimidad del propio trabajador, como al derecho al secreto de las comunicaciones y a la protección de datos de carácter personal, los cuales son reconocidos por el artículo 18 de la Constitución Española como derechos

\footnotetext{
${ }^{3}$ Llamosas Trapaga, Aida, Relaciones laborales y nuevas tecnologías de la información y de la comunicación: una relación fructífera no exenta de dificultades, ed. Dykinson, Madrid, 2015, pp. 18 y ss.

${ }^{4}$ GoERLICH PeSET, José María, "Economía digital y acción sindical", en AA.VV. Trabajo en plataformas digitales: innovación, derecho y mercado, ed. Thomson Reuters Aranzadi, Cizur Menor, 2018, pp. 592 y ss.

${ }^{5}$ MARTINEZ Fons, Daniel, El poder de control del empresario en la relación laboral, ed. CES, Madrid, 2002, pp. 153 y ss.; ThibaUlt ARANDA, Javier, "La vigilancia del uso de internet en la empresa y la protección de datos personales", Relaciones Laborales, n 5-6, 2009, p. 69; AGUT GARCIA, Carmen, "Las facultades empresariales de vigilancia y control sobre útiles y herramientas de trabajo y otros efectos de la empresa", Tribuna Social, no 163, 2004, p. 26; SÁEz LARA, Carmen, "Derechos fundamentales de los trabajadores y poderes de control del empleador a través de las tecnologías de la información y las comunicaciones", Temas Laborales, no 138, 2017, pp. 185 y ss.; MIÑARRO YANINI, Margarita, "Las facultades empresariales de vigilancia y control en las relaciones de trabajo: especial referencia a las condiciones de su ejercicio y a sus límites", Tribuna Social, n 158, 2004, p. 13.
} 
fundamentales. Como puede comprobarse, se trata de una materia en la que entran en conflicto los derechos fundamentales del trabajador frente a la libertad de empresa ${ }^{6}$.

El problema se plantea cuando el control empresarial de la prestación de trabajo favorecido por las nuevas tecnologías, interfiere también en la transmisión sindical de información, puesto que en estos casos también pueden quedar afectados otros derechos fundamentales como es el derecho de libertad sindical. Al análisis de esta materia se van a dedicar las siguientes páginas.

\section{El uso de dispositivos digitales con fines sindicales.}

Diversos preceptos del Estatuto de los Trabajadores (arts. 64.7.e), 68.d) y 81), y de la Ley Orgánica de Libertad Sindical (arts. 8.1.b), 8.1.c), 8.2.a) y 8.2.c)) reconocen a los órganos de representación unitaria, a las secciones sindicales, y a los afiliados a los sindicatos, el derecho a distribuir y publicar información de interés para los trabajadores, pero también el derecho de los trabajadores, estén afiliados o no, a recibir dicha información en la empresa mediante distintos medios y herramientas, tales como un tablón de anuncios, o un local adecuado.

Ahora bien, a la hora de regular esta materia, ambas leyes están pensando en un tipo de empresa que carece de las innovaciones proporcionadas por las nuevas tecnologías de la información y de la comunicación. Buena muestra de ello es que cuando dichas normas fueron promulgadas por primera vez, todavía no se había extendido la llamada sociedad de la información o del conocimiento. Por tanto, el legislador no pudo prever ni contemplar los múltiples problemas que la implantación de las nuevas tecnologías plantearía en el ámbito de las relaciones de los trabajadores con la empresa, con los sindicatos, o con los representantes unitarios, o incluso las consecuencias de una defectuosa utilización de las mismas por parte del trabajador ${ }^{7}$.

No podemos negar que el uso de los medios electrónicos para transmitir dicha información ha supuesto un cambio decisivo en el papel desempeñado por los órganos de representación unitaria y sindical. El tablón de anuncios tradicional ha sido sustituido

\footnotetext{
${ }^{6}$ GoÑ SEIN, José Luís, "Vulneración de derechos fundamentales en el trabajo mediante instrumentos informáticos, de comunicación y archivo de datos", en AA.VV. Nuevas tecnologías de la información y la comunicación y Derecho del Trabajo, ed. Bomarzo, Albacete, 2004, pp. 73 y ss.; FERRANDO GARCIA, Francisca María, "Vigilancia y control de los trabajadores y derecho a la intimidad en el contexto de las nuevas tecnologías", Revista de trabajo y seguridad social CEF, $\mathrm{n}^{\circ} 399,2016$, pp. 37 y ss.; CORREA CARRASCO, Manuel, "La proyección de las nuevas tecnologías en la dinámica individual y colectiva de las relaciones laborales en la empresa: su tratamiento en la negociación colectiva", Revista de Derecho Social, no 31, 2005, p. 80.

${ }^{7}$ STSJ de Extremadura de 19 de marzo de 2009 (Rec. no 1/2009).
} 
por el tablón digital o virtual ubicado en la intranet de la empresa; el correo postal ha dado paso al correo electrónico; y la información que tradicionalmente se facilitaba en el local sindical o en la asamblea, puede ser ahora transmitida de manera inmediata a través de internet o de los medios antes citados ${ }^{8}$.

El Tribunal Constitucional tuvo ocasión de pronunciarse sobre el uso sindical de los sistemas de comunicación electrónica en la empresa, y especialmente del correo electrónico, en su sentencia $n^{\circ}$ 281/2005 de 7 de noviembre, la cual ha sido objeto de un detallado análisis por parte de la doctrina científica ${ }^{9}$. En esta materia el Tribunal Constitucional es taxativo al afirmar que las empresas no están obligadas a dotarse de una infraestructura informática para uso sindical. Ahora bien, la cuestión de fondo radica no tanto en el derecho del sindicato a exigir a la empresa el establecimiento de una infraestructura informática, sino en el potencial derecho del sindicato a utilizar el sistema preexistente en la empresa, y creado para un fin productivo. Y en este punto, el Tribunal concluye que, en caso de preexistir ese sistema informático de la empresa, creado con una finalidad productiva, aquélla debe permitir su utilización por el sindicato como medio de difusión de información sindical. De ahí que los actos empresariales tendentes a obstaculizar el contenido esencial de la libertad sindical en su vertiente informativa serían contrarios a ésta, salvo que encontrasen una justificación objetiva y razonable.

En estos casos el empresario no pierde la titularidad de la herramienta de producción porque los instrumentos informáticos siguen siendo propiedad de la empresa, y dicha propiedad no resulta desatendida por su uso sindical. La cuestión se centra en establecer los límites a la utilización de estos medios electrónicos, para lo cual el Tribunal

\footnotetext{
${ }^{8}$ Roldán Martínez, Aránzazu, Herreros López, Juan Manuel, "El ejercicio de las libertades de expresión e información de los representantes de los trabajadores en la era de internet", Actualidad Laboral, $\mathrm{n}^{\circ}$ 12, 2009, pp. 1383 y ss.; NAVARRO NIETO, Federico, "El ejercicio de la actividad sindical a través de las tecnologías de la información y de las comunicaciones", Temas Laborales, $\mathrm{n}^{\circ}$ 138, 2017, pp. 51 y ss.; Almendros GonZÁlez, Miguel Ángel, "El control empresarial de la actividad de los representantes de los trabajadores", Temas Laborales, $\mathrm{n}^{\circ} 150,2019$, pp. 302 y ss.

${ }^{9}$ Sempere Navarro, Antonio Vicente, SAn Martín Mazzucconi, Carolina, "El uso sindical del correo electrónico a la luz de la STC 281/2005, de 7 de noviembre", Revista Doctrinal Aranzadi Social no 17, 2005, pp. 535 y ss.; GARCÍA NINET, Ignacio, "Sobre el uso del correo electrónico por los sindicatos utilizando los medios de la empresa, o las nuevas tecnologías al servicio de la libertad sindical. El caso COMFIA-CCOO contra BBVA-Argentaria: del "ius usus inocui" de las nuevas tecnologías", Tribuna Social, $\mathrm{n}^{\circ}$ 181, 2006, pp. 5 y ss.; TAPIA HERMIDA, Alberto, "Uso del correo electrónico para transmitir información de naturaleza laboral y sindical a los trabajadores por las organizaciones sindicales en los centros de trabajo y durante la jornada laboral, Revista de Trabajo y Seguridad Social CEF, $\mathrm{n}^{\circ}$ 276, 2006, pp. 141 y ss.; AlZAGA RUIZ, Icíar, "El uso por la representación sindical de los medios informáticos propiedad de la empresa", en AA.VV. Jurisprudencia Constitucional sobre trabajo y Seguridad Social", Tomo XXIII, ed. Civitas, Madrid, 2005, pp. 341 y ss.
} 
Constitucional fija toda una serie de condiciones, algunas de carácter subjetivo y otras de carácter material ${ }^{10}$.

Con carácter previo se parte de la base de que el derecho al uso de estos instrumentos electrónicos se reconoce al sindicato para transmitir información de naturaleza laboral y sindical, de modo que cualquier utilización con otra finalidad, quedaría fuera del amparo constitucional. Una vez sentado ello, deben respetarse los siguientes límites:

a) La comunicación no podrá perturbar la actividad normal de la empresa. En este sentido, no es posible estimar por defecto que la recepción de mensajes en la dirección de correo electrónico del trabajador en horario de trabajo produzca dicha perturbación, ya que nada impide la lectura de los mensajes al finalizar la jornada o en las pausas existentes.

b) Tratándose del empleo de un medio electrónico de comunicación creado como herramienta de producción, no podrá perjudicarse el uso específico empresarial por el que fue creado, ni pretenderse que deba prevalecer el interés de uso sindical, debiendo prevalecer el primero en caso de conflicto. A tal efecto resultaría constitucionalmente lícito que la empresa predeterminase las condiciones de utilización de las comunicaciones electrónicas para fines sindicales, siempre que no las excluyera en términos absolutos.

c) Finalmente, la utilización de los instrumentos electrónicos por parte del sindicato, no podrá ocasionar gravámenes adicionales, especialmente económicos, para el empresario. Se trata de aprovechar aquello que la empresa ya tiene, no de crear nuevos instrumentos (aumento de capacidades, cambios de programas informáticos, etc.) al servicio de las necesidades o conveniencias sindicales.

Sin embargo, dicha sentencia no se pronunció sobre el control empresarial del uso sindical de los medios informáticos, ni tampoco sobre la posible fiscalización empresarial del contenido de los correos electrónicos o de los archivos remitidos previamente por el sindicato para ser publicados en el tablón digital.

Siendo éstos los términos del debate, cabe reflexionar sobre el control empresarial del uso de dispositivos digitales, cuando son utilizados por los órganos de representación

\footnotetext{
${ }^{10}$ TASCÓN LÓPEZ, Rodrigo, "La utilización del correo electrónico corporativo de la empresa como cauce apropiado para distribuir información sindical", Revista de Trabajo y Seguridad Social CEF, $\mathrm{n}^{\circ}$ 276, 2006, p. 171 y ss.; TORRENTS MARGALEF, Jorge, "La disposición de las tecnologías de la información y comunicación al servicio de los representantes de los trabajadores", en AA VV, La negociación colectiva en España: una mirada crítica, ed. Tirant lo Blanch, Valencia, 2006, pp. 327 y ss.
} 
colectiva en el desempeño de sus funciones representativas o por el mismo sindicato en el ejercicio de actividad sindical informativa.

\section{La inexistente regulación legal sobre el control empresarial del uso de dispositivos digitales con fines sindicales.}

El ordenamiento jurídico concede al empresario toda una serie de facultades de control y de vigilancia de la prestación debida por el trabajador como manifestación de su poder de dirección, de modo que, en aplicación de lo dispuesto en el artículo 20.3 del Estatuto de los Trabajadores, el empresario podría adoptar las medidas que estime más oportunas de vigilancia y de control para verificar el cumplimiento por el trabajador de sus obligaciones y deberes laborales, guardando en su adopción y aplicación la consideración debida a su dignidad.

En esta materia ha incidido de manera decisiva la Ley Orgánica 3/2018, de 5 de diciembre, de Protección de Datos Personales y garantía de los derechos digitales cuya Disposición Final $13^{\mathrm{a}}$ ha introducido en el Estatuto de los Trabajadores un nuevo artículo (el 20.bis) que con el título: "Derechos de los trabajadores a la intimidad en relación con el entorno digital y a la desconexión", señala expresamente que los trabajadores tienen derecho a la intimidad en el uso de los dispositivos digitales puestos a su disposición por el empleador, en los términos establecidos en la legislación vigente en materia de protección de datos personales y garantía de los derechos digitales. En aras a garantizar esta protección, dicha Ley Orgánica ha establecido una regulación específica en sus artículos 87 a 90, que a su vez puede ser objeto de desarrollo por la negociación colectiva tal y como prevé el artículo 91.

Precisamente, el artículo 87 de esta Ley, con el título: "Derecho a la intimidad y uso de dispositivos digitales en el ámbito laboral", insiste en que los trabajadores tendrán derecho a la protección de su intimidad en el uso de los dispositivos digitales puestos a su disposición por el empresario, y que éste podrá acceder a los contenidos derivados de su uso a los solos efectos de controlar el cumplimiento de las obligaciones laborales y de garantizar la integridad de dichos dispositivos.

Además, el empresario deberá establecer los criterios de utilización de estos dispositivos (en cuya elaboración participarán los representantes de los trabajadores y que pueden incluir tanto el posible uso para fines privados como su duración), respetando en todo caso los estándares mínimos de protección de la intimidad de los trabajadores de acuerdo con los usos sociales y los derechos reconocidos constitucional y legalmente. 
En cualquier caso, para que el empresario pueda acceder al contenido de los dispositivos digitales respecto de los que haya admitido su uso con fines privados, será necesario que se hayan especificado previamente y de modo preciso los usos autorizados, que se establezcan garantías para preservar la intimidad de los trabajadores, y que éstos sean informados sobre dichos criterios de utilización ${ }^{11}$.

Sin embargo, no existe una regulación legal específica sobre el control empresarial del uso de los dispositivos digitales por parte de los órganos de representación unitaria o sindical, lo que ha provocado que sea la negociación colectiva y los pronunciamientos jurisprudenciales los encargados de colmar este vacío legal de una manera singular.

La negociación colectiva ha reproducido en esta materia los términos previstos para el control empresarial del uso de dispositivos digitales por parte de los trabajadores, mientras que los tribunales de justicia han abordado esta materia no tanto desde la óptica de los criterios fijados por una consolidada jurisprudencia constitucional, ordinaria y europea en materia de control empresarial del uso de dispositivos digitales en el ámbito laboral, sino desde la óptica de la superación o no de los estándares fijados por el Tribunal Constitucional en su sentencia $n^{0}$ 281/2005 de 7 de noviembre, centrándose en determinar si el uso sindical de los medios electrónicos perturbaba o no la actividad normal de la empresa, respetaba o no la finalidad empresarial para la que dichos sistemas informáticos fueron creados, o si generaba o no gravámenes adicionales para el empresario.

Tanto de la regulación convencional como del tratamiento jurisprudencial se desprende, en términos generales, que el empresario carece "a priori" de una potestad censora sobre la información distribuida por el sindicato a los afiliados o a los trabajadores en general, sin que tampoco pueda controlar el contenido de dicha información ${ }^{12}$.

\footnotetext{
${ }^{11}$ Según dicho artículo: "1. Los trabajadores y los empleados públicos tendrán derecho a la protección de su intimidad en el uso de los dispositivos digitales puestos a su disposición por su empleador. 2. El empleador podrá acceder a los contenidos derivados del uso de medios digitales facilitados a los trabajadores a los solos efectos de controlar el cumplimiento de las obligaciones laborales o estatutarias y de garantizar la integridad de dichos dispositivos. 3. Los empleadores deberán establecer criterios de utilización de los dispositivos digitales respetando en todo caso los estándares mínimos de protección de su intimidad de acuerdo con los usos sociales y los derechos reconocidos constitucional y legalmente. En su elaboración deberán participar los representantes de los trabajadores. El acceso por el empleador al contenido de dispositivos digitales respecto de los que haya admitido su uso con fines privados requerirá que se especifiquen de modo preciso los usos autorizados y se establezcan garantías para preservar la intimidad de los trabajadores, tales como, en su caso, la determinación de los períodos en que los dispositivos podrán utilizarse para fines privados. Los trabajadores deberán ser informados de los criterios de utilización a los que se refiere este apartado".

12 Sempere Navarro, Antonio Vicente, San Martin Mazzucconi, Carolina, "El uso sindical del correo electrónico a la luz de la STC 281/2005 de 7 de noviembre", ob. cit. pp. 535 y ss.; ALMENDROS
} 
Si la empresa voluntariamente entorpece u obstruye las comunicaciones sindicales, ello puede vulnerar no solo el derecho de libertad sindical, sino también el derecho al secreto de las comunicaciones (especialmente cuando se trata de mensajes particulares enviados desde el sindicato al trabajador), estando legitimado el sindicato en tales casos a interponer una demanda judicial a través del proceso de tutela de derechos fundamentales y libertades públicas ${ }^{13}$.

El control empresarial de las comunicaciones destinadas a distribuir información de naturaleza sindical solo será posible en aquellos casos en que existan fundadas sospechas de un uso desviado de los cauces de información concertados y dispuestos por el empresario, y se justificaría tan sólo para evitar ciertos riesgos derivados de un uso abusivo del mismo. Por ello deberán valorase las circunstancias de cada caso concreto, y si existe o no una normativa convencional que discipline la materia.

Además, cualquier control empresarial debiera de venir limitado por el llamado principio de proporcionalidad, que impone la aplicación del conocido test de idoneidad, necesidad y ponderación de la medida a adoptar. De modo que para comprobar si una medida restrictiva de un derecho fundamental supera el juicio de proporcionalidad, será necesario constatar si cumple los tres siguientes requisitos o condiciones y en concreto: si tal medida es susceptible de conseguir el objetivo propuesto (juicio de idoneidad); si, además, es necesaria, en el sentido de que no exista otra medida más moderada para la consecución de tal propósito con igual eficacia (juicio de necesidad); y, finalmente, si la misma es ponderada o equilibrada, por derivarse de ella más beneficios o ventajas para el interés general que perjuicios sobre otros bienes o valores en conflicto (juicio de proporcionalidad en sentido estricto) ${ }^{14}$.

\section{La regulación convencional.}

GONZÁLEZ, Miguel Ángel, "El control empresarial de la actividad de los representantes de los trabajadores", ob. cit. pp. 311 y ss.

13 Roqueta BUJ, Remedios, "El uso sindical de los sistemas de comunicación electrónica de las empresas. A propósito de la STC de 7 de noviembre de 2005", Actualidad Laboral, n 3, 2006, pp. 265 y ss.; RoldÁn MARTíneZ, Aránzazu, Herreros LOPEZ, Juan Manuel, "El ejercicio de las libertades de expresión e información de los representantes de los trabajadores en la era de internet", ob. cit. pp. 1383 y ss.; MORATO GARCÍA, Rosa María, "El control de internet y correo electrónico en la negociación colectiva", Relaciones Laborales, nº 24, 2005, pp. 1373 y ss.; PÉREZ De LOS CoBOS ORIHUEL, Francisco, "El uso sindical de los medios informáticos en la empresa", Relaciones Laborales, n 5-6, 2009, pp. 7 y ss.

${ }^{14} \mathrm{STC}^{\circ}$ 96/2012, de 7 de mayo; STC n ${ }^{\circ}$ 14/2003, de 28 de enero; STC n ${ }^{\circ}$ 89/2006, de 27 de marzo; y STC $n^{\circ} 170 / 2013$, de 7 de octubre. 
La negociación colectiva ha tenido ocasión de regular el uso del correo electrónico y de la navegación por internet en la empresa por parte de los trabajadores, así como sus límites.

Por lo que respecta al correo electrónico, la mayoría de convenios colectivos $^{15}$ contempla el uso de la cuenta de correo electrónico empresarial para fines estrictamente profesionales, prohibiendo la utilización de la misma para fines particulares o personales del trabajador. Y por lo que respecta a los límites de su uso, algunos convenios colectivos ${ }^{16}$ exigen la necesaria autorización de la empresa para que el trabajador pueda usar el correo electrónico para fines personales o particulares; un segundo grupo de convenios ${ }^{17}$ impide que el trabajador pueda enviar correos electrónicos que dañen la imagen de la empresa, que divulguen secretos de la misma o de sus clientes, o que transmitan información confidencial; un tercer grupo de convenios colectivos ${ }^{18}$ prohíbe que los trabajadores puedan usar el correo electrónico para efectuar envíos masivos de mensajes, o para remitir mensajes de gran tamaño o capacidad que perturben el normal funcionamiento de la red de comunicación en la empresa; y un cuarto grupo de convenios colectivos ${ }^{19}$ prohíbe el envío de mensajes que vulneren derechos fundamentales de la persona, o que puedan ser constitutivos de delito y más concretamente: aquellos dirigidos a difundir contenidos o imágenes ofensivas, inapropiadas o discriminatorias por razones de edad, sexo, y discapacidad; aquellos que promuevan el acoso sexual, moral o laboral; los que difunden material pornográfico; o correos de contenido violento, racista o sexista, intimidante, o difamatorio.

Por lo que respecta a la navegación por internet, la negociación colectiva también suele restringirla para fines estrictamente profesionale ${ }^{20}$, prohibiéndola en aquellos casos en que el trabajador recurre a ella para fines particulares o para desempeñar una actividad profesional distinta a la realizada en la empresa; cuando no se cuenta con la debida autorización de la empresa en aquellos casos en que sea exigible; cuando el número de

\footnotetext{
${ }^{15}$ Por todos: artículo 73 del XVI convenio colectivo de la empresa ONCE y su personal (BOE de 18 de enero de 2018).

${ }^{16}$ Artículo 77.2 del II convenio colectivo estatal de reforma juvenil y protección de menores (BOE de 27 de noviembre de 2012).

${ }^{17}$ Artículo 63 del convenio colectivo del sector fabricantes de yesos, escayolas, cales y sus prefabricados (BOE de 2 de marzo de 2016).

${ }^{18}$ Artículo 168 del convenio colectivo de empresas vinculadas a Telefónica de España, SAU, Telefónica Móviles España, SAU y Telefónica Soluciones de Informática y comunicaciones, SAU (BOE de 21 de enero de 2016).

${ }^{19}$ Artículo 77.2 del II convenio colectivo estatal de reforma juvenil y protección de menores (BOE de 27 de noviembre de 2012).

${ }^{20}$ Artículo 87.2 del XVIII convenio colectivo general de la Industria Química (BOE de 8 de agosto de 2017).
} 
accesos es excesivo o desmedido ${ }^{21}$; o cuando se accede a páginas relacionadas con el ocio o el juego, o con contenidos de tipo violento, sexista, racista o pornográfico y en definitiva contrarios a derechos fundamentales ${ }^{22}$.

Pero la negociación colectiva también ha regulado el uso del correo electrónico y de la navegación por internet por parte de la representación unitaria y sindical, así como sus límites. Y lo ha hecho reproduciendo los términos antes descritos sin fijar una regulación distinta y específica, o a lo sumo exigiendo el respeto a los límites sobre el uso sindical de los medios electrónicos en la empresa que fijó la STC no 281/2005 de 7 de noviembre.

De modo que ciertos convenios colectivos $^{23}$ exigen que los correos electrónicos enviados por la representación unitaria o sindical deban tener un contenido estrictamente laboral y relacionado con las funciones de representación colectiva, prohibiéndose la utilización del correo electrónico para fines ajenos a la actividad sindical y estrictamente particulares. Otros convenios colectivos ${ }^{24}$ exigen que el uso del correo electrónico por parte de los representantes legales sea racional o prudente y que no perturbe el normal funcionamiento de la actividad productiva, el fin específico para el que fue instalado, o la capacidad técnica del sistema, y sin que interfiera en el trabajo habitual o suponga un mayor coste económico para la empresa, pudiendo exigir ésta que el envío de correos se efectúe fuera de las horas de trabajo. E incluso determinados convenios colectivos ${ }^{25}$ exigen una autorización empresarial para el uso del correo electrónico por los representantes legales, o en cualquier caso, el acuerdo con la empresa sobre los términos y condiciones del envío de $\operatorname{correos}^{26}$, o el sometimiento a la normativa interna que pueda publicar la empresa ${ }^{27}$.

Y por lo que se refiere al acceso a internet y a la intranet de la empresa, algunos convenios colectivos ${ }^{28}$ reconocen a los representantes legales el uso de la intranet

\footnotetext{
${ }^{21}$ Artículo 61 del convenio colectivo para la prensa diaria (BOE de 28 de febrero de 2018).

${ }^{22}$ Capítulo XV del Acuerdo interprofesional de Cataluña para los años 2018-2020 (DOGC de 7 de septiembre de 2018).

${ }^{23}$ Artículo 583 del XV convenio colectivo de RENFE (BOE de 22 de marzo de 2005).

${ }^{24}$ Artículo 80 del convenio colectivo general de ámbito estatal para el sector de entidades de seguros, reaseguros y mutuas colaboradoras con la Seguridad Social (BOE de 1 de junio de 2017).

${ }^{25}$ Artículo 51 del convenio colectivo para la prensa diaria (BOE de 28 de febrero de 2018).

${ }^{26}$ Artículo 61 del VI convenio colectivo estatal para las empresas de gestión y mediación inmobiliaria (BOE de 2 de enero de 2017).

${ }^{27}$ Artículo 53 del IV convenio colectivo autonómico para la industria de azulejos, pavimentos y baldosas cerámicas de la Comunidad Valenciana (DOGV de 26 de diciembre de 2018).

${ }^{28}$ Artículo 217 del convenio colectivo de empresas vinculadas a Telefónica de España, SAU, Telefónica Móviles España, SAU y Telefónica Soluciones de Informática y comunicaciones, SAU (BOE de 21 de enero de 2016).
} 
empresarial para que puedan crear dentro de ella un portal sindical donde colgar la información de interés para los trabajadores.

El control empresarial del uso de dispositivos digitales en el ámbito laboral también ha sido objeto de regulación por la negociación colectiva ${ }^{29}$. Las previsiones convencionales sobre el control del uso del correo electrónico y de internet suelen ser comunes, sin olvidar que mientras la navegación por internet supone el acceso abierto a toda una información disponible en la red, por el contrario, los mensajes enviados y recibidos mediante el correo electrónico están protegidos por el secreto de las comunicaciones ${ }^{30}$.

En términos generales, los convenios colectivos $^{31}$ suelen condicionar el control empresarial del uso de internet o del correo electrónico tan sólo a aquellos casos en que existan indicios razonables de un uso abusivo o indebido de la dirección de correo electrónico o de internet para fines privados y no laborales. Apreciados tales indicios, los mecanismos de control suelen variar, y pueden consistir en la realización de las oportunas comprobaciones sobre el número de correos electrónicos enviados y recibidos, así como sobre las direcciones a las que se han remitido los mismos. E incluso, si fuera preciso, dichas inspecciones pueden consistir en la realización de una auditoria en el ordenador del empleado.

Algunos convenios colectivos ${ }^{32}$, también permiten a las empresas introducir "software" de control automatizado para verificar el material creado, almacenado, recibido o enviado en la red, pudiendo revisar historiales de navegación y de correos electrónicos enviados y recibidos. Se trata de programas de gestión de la utilización del correo electrónico instalados en los terminales y que también permiten establecer filtros de seguridad en los servidores y el bloqueo de determinadas direcciones de internet o palabras relacionadas con aspectos confidenciales de la empresa.

\footnotetext{
${ }^{29}$ Véase: Morato García, Rosa María, "El control de internet y correo electrónico en la negociación colectiva", ob. cit. pp. 1373 y ss.; NIEVES NIETo, Núria, "El uso del correo electrónico e internet en la negociación colectiva", Relaciones Laborales, $\mathrm{n}^{\circ}$ 5-6, 2009, pp. 249 y ss.

${ }^{30}$ FeRnÁndeZ VILLAZÓn, Luis Antonio, Las facultades empresariales de control de la actividad laboral, ed. Aranzadi, Cizur Menor, 2003, p. 144.

${ }^{31}$ Artículo 168 del convenio colectivo de empresas vinculadas a Telefónica de España, SAU, Telefónica Móviles España, SAU y Telefónica Soluciones de Informática y Comunicaciones, SAU (BOE de 21 de enero de 2016).

${ }^{32}$ Artículo 63 del convenio colectivo del sector fabricantes de yesos, escayolas, cales y sus prefabricados (BOE de 2 de marzo de 2016).
} 
Y como garantías para el trabajador, la negociación colectiva ${ }^{33}$ ha entendido que el control empresarial del uso del ordenador se realizará siempre respetando en todo momento las previsiones contenidas en las normas sobre protección de datos de carácter personal. Además, dichas medidas deberán ser proporcionales a la finalidad de verificar el cumplimiento por parte del trabajador de sus obligaciones y deberes laborales, y deberán respetar su dignidad y su intimidad, siendo preceptivo que se cumpla con los deberes de información previa a los trabajadores afectados previstos en la legislación vigente $^{34}$.

Por lo que se refiere al control empresarial de los correos electrónicos enviados entre los representantes legales y los trabajadores, los mismos también se considerarán confidenciales, no pudiendo la empresa proceder a su revisión, excepto por causas excepcionales que así lo justificasen y previa notificación al comité de empresa ${ }^{35}$. Y aunque la empresa puede efectuar un control técnico de los mismos, deberá respetar en todo caso la protección de datos de carácter personal ${ }^{36}$.

Y por lo que se refiere al control empresarial sobre las visitas a páginas o portales web, los mismos suelen coincidir con los expuestos para los envíos de mensajería electrónica, de manera que algunos convenios colectivos prevén que las empresas puedan establecer mecanismos de detección de los sitios de internet visitados por cada usuario. Y al igual que sucedía con el correo electrónico, el uso indebido de internet, también puede constituir una conducta reprobable por la empresa ${ }^{37}$.

La instalación empresarial de programas dirigidos a controlar el uso de la navegación puede suponer principalmente un atentado al derecho a la intimidad del trabajador o del representante unitario o sindical, máxime si el programa se instala de forma oculta ignorando el trabajador su conocimiento. Pero ello no significa que el empresario deba soportar la pérdida de actividad laboral por el ejercicio privado y no consentido de la navegación por internet, y estará facultado para llevar a cabo una vigilancia cuando haya detectado irregularidades en el uso de internet y no sea posible satisfacer sus

\footnotetext{
${ }^{33}$ Artículo 8.9 del XVIII convenio colectivo general de la Industria Química (BOE de 8 de agosto de 2018).

${ }^{34}$ Artículo 168 del convenio colectivo de empresas vinculadas a Telefónica de España, SAU, Telefónica Móviles España, SAU y Telefónica Soluciones de Informática y Comunicaciones, SAU (BOE de 21 de enero de 2016).

${ }^{35}$ NiEVES NIETO, Núria, "El uso del correo electrónico e internet en la negociación colectiva", ob. cit. pp. 249 y ss.

${ }^{36}$ Artículo 61 del VI convenio colectivo estatal para las empresas de gestión y mediación inmobiliaria (BOE de 2 de enero de 2017).

${ }^{37}$ Thibault ARANDA, Javier, "La vigilancia del uso de internet en la empresa y la protección de datos personales", ob. cit. p. 69.
} 
intereses mediante otros procedimientos distintos del control ${ }^{38}$. Ahora bien, para poder llevar a cabo dichas revisiones, nuevamente deberán existir indicios razonables de un uso indebido, y también deberá respetarse por el empresario las reglas que configuran el principio de proporcionalidad ${ }^{39}$.

\section{El tratamiento jurisprudencial.}

El control empresarial sobre el uso de los medios de comunicación electrónica en el ámbito laboral ha dado pie a una importante jurisprudencia emanada del Tribunal Supremo, del Tribunal Constitucional y del Tribunal Europeo de Derechos Humanos, que interesa abordar (siquiera tangencialmente), antes de efectuar cualquier reflexión sobre la fiscalización empresarial de los dispositivos digitales con fines sindicales.

La jurisprudencia del Tribunal Supremo ${ }^{40}$ en materia de control empresarial sobre el uso de los medios electrónicos por parte los trabajadores, puede resumirse del siguiente modo: a) la empresa debe dejar claro e informar al trabajador que el contenido del ordenador o de las comunicaciones puede ser examinado, de donde se desprende la necesidad de que haya una política de uso y control de las herramientas informáticas; b) son válidas las prohibiciones absolutas del uso personal de las herramientas informáticas, y esta prohibición absoluta descarta cualquier margen de tolerancia para el uso personal del correo electrónico y rompe toda expectativa de intimidad, al tiempo que comporta la implícita advertencia sobre su posible control y neutraliza igualmente el secreto de las comunicaciones; c) a la hora de llevar a cabo el control empresarial se deben tener en cuenta los tradicionales criterios de idoneidad, necesidad y proporcionalidad de la medida de control utilizada.

Por lo que se refiere al Tribunal Constitucional, éste también ha tenido ocasión de pronunciarse al respecto $^{41}$. A juicio del Tribunal, es perfectamente admisible la

${ }^{38}$ GoÑ SEIN, José Luis, "Vulneración de derechos fundamentales en el trabajo mediante instrumentos informáticos, de comunicación y archivo de datos", ob. cit. pp. 73 y ss.

39 Morato García, Rosa María, "El control de internet y correo electrónico en la negociación colectiva", ob. cit. pp. 137 y ss.

${ }^{40}$ Entre otras: STS de 26 de septiembre de 2007 (Rec. $n^{\circ}$ 966/2006) en un supuesto en que el trabajador había sido despedido por acceder de manera recurrente a páginas pornográficas desde un ordenador de la empresa; STS de 8 de marzo de 2011 (Rec. $\mathrm{n}^{\circ}$ 1826/2010) en un supuesto en que el trabajador es despedido tras comprobarse en una auditoría que había efectuado en horas de trabajo más de 5000 visitas a páginas de contenido extra laboral; y STS de 6 de octubre de 2011 (Rec. $n^{\circ}$ 4053/2010) en un supuesto en que un trabajador es despedido por el uso indebido del ordenador de la empresa detectado mediante un sistema de control pasivo.

${ }^{41}$ En la sentencia n ${ }^{\circ} 170 / 2013$, de 7 de octubre, el Tribunal se pronuncia sobre un supuesto en que un trabajador es despedido disciplinariamente en base al contenido de los correos electrónicos en los que proporcionaba información confidencial a la competencia, cuando el convenio colectivo prohibía 
ordenación y regulación del uso de los medios informáticos de titularidad empresarial, así como la facultad empresarial de vigilancia y control del cumplimiento de las obligaciones relativas a la utilización del medio en cuestión, siempre con pleno respeto a los derechos fundamentales y al principio de proporcionalidad ${ }^{42}$. Además, no puede haber expectativa razonable y fundada de intimidad cuando exista una prohibición convencional del uso extra laboral de los medios informáticos que lleva implícito el poder fiscalizador del empresario. Ello significa que si el convenio colectivo aplicable tan sólo permite el uso del correo electrónico por parte del trabajador con fines profesionales y no personales, el poder de control empresarial "ex" artículo 20.3 del Estatuto de los Trabajadores puede legítimamente ejercerse, y el acceso por la empresa a los correos electrónicos del trabajador reuniría las exigencias requeridas por el juicio de proporcionalidad ${ }^{43}$.

Por lo que se refiere al Tribunal Europeo de Derechos Humanos, existen varios pronunciamientos de interés ${ }^{44}$. Con carácter general este Tribunal $^{45}$ ha censurado la recogida y almacenamiento de información efectuada por la empresa sobre correos electrónicos y navegación por internet sin que el trabajador lo supiera ya que esa conducta implica una injerencia en la vida privada y en la confidencialidad de la correspondencia. Entiende este Tribunal que los correos electrónicos enviados desde el

expresamente el uso del ordenador para fines privados. Y en la sentencia $\mathrm{n}^{\mathrm{o}}$ 241/2012, de 17 de diciembre, el Tribunal dirime un supuesto en que los trabajadores de una empresa, pese a la expresa prohibición empresarial, habían instalado en un ordenador de uso compartido y sin clave de acceso, un programa de mensajería en el que criticaban incluso insultaban a compañeros y clientes. Según el Tribunal Constitucional el control del ordenador no vulneró el derecho a la intimidad desde el mismo momento en que los trabajadores realizaron actos dispositivos que eliminaron la privacidad de sus conversaciones al incluirlas en el disco de un ordenador compartido, pudiendo ser leídas por cualquier otro usuario. Ni tampoco se vulneró el secreto de las comunicaciones entre los trabajadores afectados, debido a que las comunicaciones entre ellos se produjeron al introducirse el programa en un suporte de uso común, sin ningún tipo de cautela, quedando consecuentemente fuera de la protección constitucional, por tratarse de formas de envío que se configuran legalmente como comunicación abierta.

${ }^{42}$ Véase: CARrasco Duran, Manuel, "El Tribunal Constitucional y el uso del correo electrónico y los programas de mensajería en la empresa”, Revista Doctrinal Aranzadi Social, no 9, 2014, pp. 4 y ss.

43 Véase: Monereo PÉreZ, José Luis, LOPEZ InsÚA, Belén, "El control empresarial del correo electrónico tras la STC 170/2013", Revista Doctrinal Aranzadi Social, no 11, 2014, pp. 19 y ss.; RODRÍGUEZ ESCANCIANO, Susana, "El control empresarial del correo electrónico de los trabajadores: posibilidades y límites (a propósito de la STC de 7 de octubre de 2013)”, Relaciones Laborales, $\mathrm{n}^{\circ} 10$, 2014, pp. 125 y ss.

44 STEDH de 3 de abril de 2007 (Copland contra Reino Unido); STEDH de 12 de enero de 2016 (Barbulescu contra Rumanía); y STEDH de 5 de septiembre de 2017 (Barbulescu II). Véase: PÉREZ DE LOS CoBos ORIHUEL, Francisco, "El control empresarial sobre las comunicaciones electrónicas del trabajador: criterios convergentes de la jurisprudencia del Tribunal Constitucional y del Tribunal Europeo de Derechos Humanos", Revista Española de Derecho del Trabajo, n 196, 2017, pp. 41 y ss.

${ }^{45}$ STEDH de 3 de abril de 2007. 
lugar del trabajo están incluidos en el ámbito de protección del artículo 8 del Convenio europeo para la protección de los derechos humanos y de las libertades fundamentales, por cuanto pueden contener datos sensibles que afecten a la intimidad y al respeto a la vida privada. Ahora bien, la expectativa de intimidad en el uso de una herramienta informática desaparece si la empresa advierte previamente al trabajador sobre la posibilidad de fiscalizar el correo electrónico ${ }^{46}$. En recientes pronunciamientos ${ }^{47}$ este mismo Tribunal ha tenido ocasión de pronunciarse sobre la posibilidad de que el empresario pueda controlar las comunicaciones electrónicas de un trabajador, y ha precisado que cualquier fiscalización de este tipo debería tener en cuenta: a) si el empleado fue informado por su empresa de que existían medidas de vigilancia de sus comunicaciones; b) cuál fue el alcance de la supervisión realizada y si se limitó a constatar el flujo de comunicaciones o si se accedió también a su contenido; c) si existía una justificación empresarial para la vigilancia efectuada; d) si existían medios menos intrusivos que los utilizados por el empresario para conseguir el objetivo propuesto; e) cuál fue el uso que hizo el empresario de la información obtenida; y f) las garantías ofrecidas al trabajador, incluida la información previa de la posible revisión ${ }^{48}$.

Por lo que se refiere al control empresarial del uso de dispositivos digitales por parte del sindicato o de las representaciones colectivas de trabajadores, la jurisprudencia ordinaria también ha tenido ocasión de pronunciarse al respecto. Sin embargo los pronunciamientos judiciales no se basan tanto en los criterios fijados anteriormente a la hora de abordar el control empresarial del uso de dispositivos digitales en el ámbito laboral, sino en la extralimitación o no de las reglas de uso sindical de los medios electrónicos que estableció la STC no 281/2005, de 7 de noviembre. A partir de aquí, se ha sentado una doctrina dispar, y así, mientras algunos pronunciamientos aceptan el control empresarial del uso de los dispositivos electrónicos con fines sindicales en determinados supuestos, otros lo rechazan abiertamente.

En base a la primera de estas líneas jurisprudenciales el Tribunal Supremo ${ }^{49}$, ha entendido que si el convenio colectivo legitima el derecho de la empresa a "controlar el uso adecuado" de los sistemas electrónicos de comunicación sindical fijando los criterios y prioridades necesarios para garantizar el normal funcionamiento de la red

\footnotetext{
${ }^{46}$ STEDH de 12 de enero de 2016.

${ }^{47}$ STEDH de 5 de septiembre de 2017.

${ }^{48}$ La STS de 8 de febrero de 2018 (Rec. $n^{\circ} 1121 / 2015$ ) considera que la doctrina fijada por el TEDH en el caso Barbulescu II es sustancialmente coincidente con la jurisprudencia constitucional española, ya que ambas tienen como objetivo cohonestar el derecho a la vida privada y al secreto de las comunicaciones del trabajador con la facultad empresarial de comprobar la actividad profesional de sus trabajadores. Y sus criterios son perfectamente compatibles y coherentes con los tres principios tradicionales de la doctrina constitucional española (idoneidad, necesidad y proporcionalidad).

${ }^{49}$ STS de 28 de marzo de 2003 (Rec. no 81/2002).
} 
corporativa, no constituye una vulneración del derecho fundamental a la libertad sindical el que la empresa pueda llevar a cabo un control mínimo de las materias transmitidas si con ello se persigue conseguir el normal funcionamiento del sistema informático y evitar de este modo una acumulación exagerada de información. Por tal motivo, resulta razonable que la empresa pueda constatar de qué envíos se trata, sin que quepa entender que con ello se quebrante el secreto de las comunicaciones.

En otros pronunciamientos, el Tribunal Supremo ${ }^{50}$ ha señalado que el establecimiento por parte del empresario de sistemas de control aleatorio de las páginas de internet visitadas y de los correos electrónicos enviados por el sindicato a los trabajadores, no vulnera el derecho a la intimidad personal ni el secreto de las comunicaciones, o el derecho a la libertad sindical, cuando dicho control viene fijado para prevenir fines ilícitos.

Y también ha afirmado ${ }^{51}$ que no supone una lesión del derecho fundamental a la libertad sindical, la existencia de un filtro o control previo por parte de la empresa que impida o limite el envío de e-mails masivos desde los servicios de correo de los sindicatos a los buzones de correo corporativo, ya que en tales casos no estaríamos ante limitaciones desproporcionadas ni ante un impedimento del uso del correo electrónico. Así lo habría entendido también la doctrina judicial ${ }^{52}$ aceptando ciertos filtros en el uso del correo electrónico siempre que sean razonables, y con el objetivo de evitar los correos masivos, como por ejemplo exigir al emisor del correo que facilite un mecanismo que permita a cada destinatario rechazar (si lo desea), el mensaje recibido.

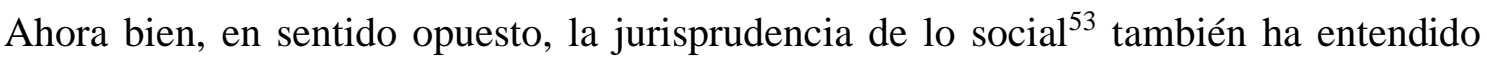
que vulnera el derecho de libertad sindical la negativa injustificada de la empresa de permitir el uso del correo electrónico existente a un determinado sindicato, cuando no concurren circunstancias que pudieran justificar esa negativa; cuando ya había reconocido ese mismo derecho a otros sindicatos; y cuando no consta que su utilización supusiera un gravamen o incremento de costes para la empresa, ni que perjudicase el normal desarrollo de la actividad productiva.

Desde esta perspectiva algunos pronunciamientos judiciales ${ }^{54}$ han interpretado que se vulnera el derecho de libertad sindical cuando la empresa establece un filtro que impide la remisión de mensajes desde la cuenta de correo electrónico del sindicato a los

\footnotetext{
${ }^{50}$ STS de 13 de septiembre de 2016 (Rec. $n^{\circ}$ 206/2015).

${ }^{51}$ STS de 24 de marzo de 2015 (Rec. $n^{\circ}$ 118/2014).

${ }^{52}$ SAN de 13 de noviembre de 2013 (Proc. no 343/2013).

${ }^{53}$ STS de 21 de febrero de 2019 (Rec. $n^{\circ}$ 214/2017).

${ }^{54}$ SAN de 10 de octubre de 2014 (Proc. $n^{\circ}$ 207/2014).
} 
trabajadores, sin que quede probado o demostrado que dicho filtro sea preciso por razones de coste o de limitación de la capacidad de la red empresarial.

Y la jurisprudencia ordinaria ${ }^{55}$, pero también la doctrina judicial ${ }^{56}$, han entendido que vulnera el derecho de libertad sindical el incumplimiento por parte de la empresa del compromiso que había adquirido por conciliación judicial en un procedimiento de conflicto colectivo, de publicar en la intranet corporativa los comunicados emitidos por las secciones sindicales existentes sin ejercer el veto o control sobre la legalidad de los mismos y su veracidad, o sobre si los mismos excedían o no los límites informativos. $\mathrm{O}$ cuando la empresa bloquea y retrasa las notas y comunicados colgados por el sindicato en la intranet corporativa impidiendo que éstas lleguen a la plantilla, incumpliendo con ello el acuerdo colectivo vigente en materia sindical ${ }^{57}$.

\section{Conclusiones.}

I. Las nuevas tecnologías de la información y de la comunicación han abierto nuevos campos a la acción sindical y la han beneficiado directamente al facilitar la labor informativa del sindicato en el seno de la empresa a través del correo electrónico, el tablón digital o la conexión a internet. La STC $n^{\circ}$ 281/2005, de 7 de noviembre estableció unas reglas al respecto, afirmando que si bien no es obligatorio que las empresas deban dotarse de una infraestructura informática para la transmisión sindical de información, en cambio, de existir ésta previamente, no puede negarse por el empresario su puesta a disposición del sindicato, ni puede unilateralmente privarse a los sindicatos de su empleo, ya que la obstaculización empresarial injustificada en el uso de dichos medios podría constituir una vulneración del derecho de libertad sindical. El Tribunal Constitucional también precisó que el uso sindical de los sistemas de comunicación electrónica en las empresas podrá ser objeto de pacto o de negociación colectiva, pero en cualquier caso dicho uso: a) no podrá perturbar la actividad normal de la empresa; b) deberá respetar siempre la finalidad empresarial para la que dichos sistemas informáticos fueron creados; y c) no podrán generar gravámenes adicionales (especialmente económicos), para el empresario.

II. El control empresarial del uso de dispositivos digitales en el ámbito laboral se encuentra previsto básicamente en la Ley Orgánica 3/2018, de 5 de diciembre, de Protección de Datos Personales y garantía de los derechos digitales. Sin embargo, no existe una regulación legal específica sobre el control empresarial del uso de los dispositivos digitales por parte de los órganos de representación unitaria o sindical, lo

\footnotetext{
${ }^{55}$ STS de 2 de noviembre de 2016 (Rec. n $^{\circ}$ 262/2015).

${ }^{56}$ SAN de 27 de mayo de 2015 (Proc. no 83/2014); SAN de 15 de junio de 2015 (Proc. n $^{\circ}$ 117/2015).

${ }^{57}$ STS de 15 de enero de 2019 (Rec. $\mathrm{n}^{\circ}$ 220/2017).
} 
que ha provocado que sea la negociación colectiva y los pronunciamientos jurisprudenciales, los encargados de colmar este vacío legal.

III.- La negociación colectiva ha fijado las reglas y los límites en el uso de los dispositivos digitales por parte del sindicato y de los órganos de representación colectiva de los trabajadores. De igual modo ha establecido las garantías en los controles empresariales sobre dichos dispositivos. Pero en términos generales, la regulación pactada no difiere en exceso de la prevista con carácter general para el control empresarial del uso de dispositivos digitales en el ámbito laboral.

IV. Sin embargo, los pronunciamientos jurisprudenciales han abordado esta cuestión de manera diversa al tratamiento general dado por la jurisprudencia ordinaria, constitucional y europea en materia de control empresarial de los dispositivos digitales en el ámbito laboral, y partiendo de la STC no 281/2005 de 7 de noviembre como punto de referencia, han mantenido criterios dispares a la hora de aceptar o de rechazar el control empresarial de los dispositivos electrónicos con fines sindicales, admitiéndolo en algunos casos e impidiéndolo en otros según si el uso sindical de los medios electrónicos perturbaba o no la actividad normal de la empresa, respetaba o no la finalidad empresarial para la que dichos sistemas informáticos fueron creados, o si generaba o no gravámenes adicionales para el empresario.

V. Visto el tratamiento efectuado por la negociación colectiva y por los tribunales de justicia, se puede afirmar que el empresario carece "a priori" de una potestad censora sobre la información distribuida por el sindicato a los afiliados o a los trabajadores en general a través de medios electrónicos, sin que tampoco pueda controlar el contenido de dicha información. Si la empresa voluntariamente entorpece u obstruye las comunicaciones sindicales, ello puede vulnerar no solo el derecho al secreto de las comunicaciones sino también el derecho de libertad sindical.

VI. El control empresarial de las comunicaciones destinadas a distribuir información de naturaleza sindical solo será posible en aquellos casos en que existan indicios razonables o fundadas sospechas de un uso desviado de los mecanismos de información, y se justificaría tan sólo para evitar ciertos riesgos derivados de un uso abusivo de los mismos. Y para llevar a cabo cualquier tipo de control sobre el uso de dispositivos digitales con fines sindicales, el empresario deberá respetar el llamado principio de proporcionalidad, de modo que deberá verificar si tal medida es susceptible de conseguir el objetivo propuesto (juicio de idoneidad); si, además, es necesaria, en el sentido de que no exista otra medida más moderada para la consecución de tal propósito con igual eficacia (juicio de necesidad); $\mathrm{y}$, finalmente, si la misma es ponderada o equilibrada, por derivarse de ella más beneficios o ventajas para el interés general que 
perjuicios sobre otros bienes o valores en conflicto (juicio de proporcionalidad en sentido estricto).

\section{Bibliografía.}

AGUT GARCIA, Carmen, "Las facultades empresariales de vigilancia y control sobre útiles y herramientas de trabajo y otros efectos de la empresa", Tribuna Social, $\mathrm{n}^{\circ} 163$, 2004.

ALMENDROS GONZÁLEZ, Miguel Ángel, "El control empresarial de la actividad de los representantes de los trabajadores", Temas Laborales, n 150, 2019.

AlzAGA RUIZ, Icíar, "El uso por la representación sindical de los medios informáticos propiedad de la empresa", en AA.VV. Jurisprudencia Constitucional sobre trabajo y Seguridad Social", Tomo XXIII, ed. Civitas, Madrid, 2006.

CARrasco Duran, Manuel, "El Tribunal Constitucional y el uso del correo electrónico y los programas de mensajería en la empresa", Revista Doctrinal Aranzadi Social, nº 9, 2014.

Correa CARrasco, Manuel, "La proyección de las nuevas tecnologías en la dinámica individual y colectiva de las relaciones laborales en la empresa: su tratamiento en la negociación colectiva", Revista de Derecho Social, n 31, 2005.

FERNÁNDEZ VILLAZÓN, Luis Antonio, Las facultades empresariales de control de la actividad laboral, ed. Aranzadi, Cizur Menor, 2003.

FERRANDO GARCIA, Francisca María, "Vigilancia y control de los trabajadores y derecho a la intimidad en el contexto de las nuevas tecnologías", Revista de trabajo y seguridad social CEF, $\mathrm{n}^{\mathrm{o}} 399,2016$.

GARCía NinET, Ignacio, "Sobre el uso del correo electrónico por los sindicatos utilizando los medios de la empresa, o las nuevas tecnologías al servicio de la libertad sindical. El caso COMFIA-CCOO contra BBVA-Argentaria: del "ius usus inocui" de las nuevas tecnologías", Tribuna Social, n 181, 2006.

Goerlich Peset, José María, "Economía digital y acción sindical", en AA.VV. Trabajo en plataformas digitales: innovación, derecho y mercado, ed. Thomson Reuters Aranzadi, Cizur Menor, 2018. 
GoÑI SEIN, José Luis, "Vulneración de derechos fundamentales en el trabajo mediante instrumentos informáticos, de comunicación y archivo de datos", en AA.VV. Nuevas tecnologías de la información y la comunicación y Derecho del Trabajo, ed. Bomarzo, Albacete, 2004.

Llamosas TRAPAGA, Aida, Relaciones laborales y nuevas tecnologías de la información y de la comunicación: una relación fructífera no exenta de dificultades, ed. Dykinson, Madrid, 2015.

MARTINEZ FONS, Daniel, El poder de control del empresario en la relación laboral, ed. CES, Madrid, 2002.

MiÑARRO YANINI, Margarita, "Las facultades empresariales de vigilancia y control en las relaciones de trabajo: especial referencia a las condiciones de su ejercicio y a sus límites", Tribuna Social, no 158.

Monereo PÉREZ, José Luis, LOPEZ InsÚA, Belén, "El control empresarial del correo electrónico tras la STC 170/2013”, Revista doctrinal Aranzadi Social, nº 11, 2014.

Morato GARcía, Rosa María, "El control de internet y correo electrónico en la negociación colectiva", Relaciones Laborales, n² 24, 2005.

NAVARro NiETO, Federico, "El ejercicio de la actividad sindical a través de las tecnologías de la información y de las comunicaciones", Temas Laborales, $\mathrm{n}^{\circ} 138$, 2017.

NiEVES NIETO, Núria, "El uso del correo electrónico e internet en la negociación colectiva", Relaciones Laborales, no 5-6, 2009.

PÉREZ De Los CoBos ORIHUEL, Francisco, "El control empresarial sobre las comunicaciones electrónicas del trabajador: criterios convergentes de la jurisprudencia del Tribunal Constitucional y del Tribunal Europeo de Derechos Humanos", Revista Española de Derecho del Trabajo, nº 196, 2017.

Pérez De Los Cobos OrIHUel, Francisco, "El uso sindical de los medios informáticos en la empresa", Relaciones Laborales, n 5-6, 2009.

RODRÍGUEZ ESCANCIANO, Susana, "El control empresarial del correo electrónico de los trabajadores: posibilidades y límites (a propósito de la STC de 7 de octubre de 2013)", Relaciones Laborales, $\mathrm{n}^{\circ}$ 10, 2014. 
RoldÁn MARTínez, Aránzazu, Herreros LóPEZ, Juan Manuel, "El ejercicio de las libertades de expresión e información de los representantes de los trabajadores en la era de internet", Actualidad Laboral, nº 12, 2009.

Roqueta Buj, Remedios, "El uso sindical de los sistemas de comunicación electrónica de las empresas. A propósito de la STC de 7 de noviembre de 2005", Actualidad Laboral, $\mathrm{n}^{\circ}$ 3, 2006.

SÁEz LARA, Carmen, "Derechos fundamentales de los trabajadores y poderes de control del empleador a través de las tecnologías de la información y las comunicaciones", Temas Laborales, $\mathrm{n}^{\mathrm{o}}$ 138, 2017.

Sempere Navarro, Antonio Vicente, San Martín Mazzucconi, Carolina, "El uso sindical del correo electrónico a la luz de la STC 281/2005, de 7 de noviembre", Revista Doctrinal Aranzadi Social, no 17, 2005.

TAPIA HERMIDA, Alberto, "Uso del correo electrónico para transmitir información de naturaleza laboral y sindical a los trabajadores por las organizaciones sindicales en los centros de trabajo y durante la jornada laboral", Revista de trabajo y seguridad social $C E F, \mathrm{n}^{\mathrm{o}} 276,2006$.

TASCÓN LÓPEZ, Rodrigo, "La utilización del correo electrónico corporativo de la empresa como cauce apropiado para distribuir información sindical", Revista de Trabajo y Seguridad Social CEF, nº 276, 2006.

ThiBAult ARANDA, Javier, "La vigilancia del uso de internet en la empresa y la protección de datos personales", Relaciones Laborales, n 5-6, 2009.

TORRENTS MARGALEF, Jorge, "La disposición de las tecnologías de la información y comunicación al servicio de los representantes de los trabajadores", en AA.VV. La negociación colectiva en España: una mirada crítica, ed. Tirant lo Blanch, Valencia, 2006. 